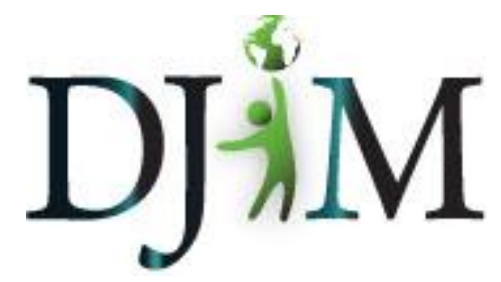

Volume 5 - Spring 2009 djim.management.dal.ca

\title{
New Textual Formats: \\ Reading Online is Re-wiring the Human Brain and Changing how we Process Information
}

\begin{abstract}
The experience of reading online is different from reading the hard copy of a printed item. This is relevant to librarians and those in the information studies field who need to be aware that the way young people and future generations read and interact with text differs from that of previous generations, especially among individuals who have been immersed in electronic media from a young age. Emerging research shows that the brain of an individual who has been surrounded by digital media from a young age develops differently than the brain of an individual who does not have an extensive history of online participation. Patterns are also beginning to emerge regarding changing brain structure in "late adopters" of online reading -- those of pre-Net Generation age who are now immersing themselves in electronic text. Librarians, teachers, and others involved in managing access to digital text and promoting literacy should be aware of these trends in order to address them effectively in their work.
\end{abstract}

\begin{abstract}
About the Author: Lara Killian has a BA in English and Philosophy from Boston College (US), and an MA in Literature from Durham University (UK). She is a first year student in the MLIS program at Dalhousie University, and has worked in a variety of different libraries. Lara is fascinated by the effect that increased exposure to text in digital formats is having both on the reader's comprehension of the material, and on the physiognomy of the reader's brain itself. This paper was researched and written for a required course, Information in Society.
\end{abstract}




\title{
New Textual Formats: \\ Reading Online is Re-wiring the Human Brain and Changing how we Process Information
}

\begin{abstract}
There are many reasons to believe that what we are seeing is the first case of a generation that is growing up with brains that are wired differently from those of the previous generation. Evidence is mounting that Net Geners process information and behave differently because they have indeed developed brains that are functionally different from those of their parents.
\end{abstract}

(Tapscott, 2009, p. 29)

Reading electronically is a different experience from that of reading a physical book, newspaper, or magazine. How does the brain process the information it is given, and is an increase in exposure to digital sources changing the way the human brain functions? The next generation of Internet users is growing up surrounded by electronic media, and researchers are starting to ask questions about how the "Net Generation" may be using their brains differently. Does exposure to increasing amounts of information actually make people smarter, or does this exposure simply give our brains more to filter through, detracting from overall learning? Finally, can we learn to find a balance between reading online and reading offline? This article will take a look at some of the most recent viewpoints in this area of research and social commentary, and will consider the origins of this shift in reading practices. The author's goal is to prompt further conversation, reading, and thought on this topic, rather than come to a single conclusion about the effect that reading online is having on the human brain.

\section{Experience of reading online vs. print formats}

The experience of reading online today is different from reading the hard copy of a printed item. There is the immediate difference in physical format, of course. Even with developments in electronic text readers, not all readers relish the idea of staring at a digital screen while perusing a novel-length text. Yet we are doing more and more reading online, rather than sitting at length with traditional newspapers or full-length books. Steven Johnson (2005) notes that even particularly avid readers are spending more and more time with electronic media -and there are only so many hours in the day for reading in various formats, especially when faced with many other digital distractions.

Nicholas Carr notes in his book, The Big Switch: Rewiring the World From Edison to Google (2008a), that when the World Wide Web (WWW) first came into existence, reading online, in the basic electronic format, was much like flipping the pages of a magazine. It didn't take long for the model of the linear textual format to give way to the WWW as we know it today: an often chaotic and disorganized collection of information, both textual and image-based, with little overarching organization. The possibility of linking electronic text to anything and everything was enticing, and HyperText Markup Language (HTML) texts proliferated. Rather than start at the top of a page of text and read it all the way through, users skip around, following one link and then another, and often failing to return to their starting point. Moving 
between parts of a text is not a new reader behavior, but in digital environments the ease of moving between snippets of information may impede the brain's ability to assimilate and later access that information. Maryanne Wolf, Director of the Center for Reading and Language Research at Tufts University, writes:

Reading is a neuronally and intellectually circuitous act, enriched as much by the unpredictable indirections of a reader's inferences and thoughts, as by the direct message to the eye from the text. / This unique aspect of reading has begun to trouble me considerably as I consider the Google universe of my children. (2007, p. 16)

Wolf recognizes that reader behavior is changing with reference to electronic texts, and she is one of a number of researchers who is examining the implications for literacy.

These days, while reading online "we seem impelled to glide across the slick surface of data as we make our rushed passage from link to link" (Carr, 2008a, p. 228). If undertaken on mental autopilot, a journey through the Internet's content lacks the conscious seeking of information; ideally, responsible users should avoid indiscriminate "clicking absentmindedly" (Johnson, 1997, p.123). In Interface Culture, an early exploration of the effects of human interaction with developing Internet applications, Johnson comments that a great deal of mental concentration is required for dealing with online text: "moving through a hypertext space, following links of association, is an intensely focused activity" (1997, p. 130). As the Internet has expanded greatly since the time of Johnson's publication, distraction abounds, and that intense focus is easily lost.

Each format has its distinct advantages: "Physical books are extremely durable information sources," however, they can't do everything, and there are "constraints on paper books that limit how far the knowledge they carry is carried," while an HTML book provides options that paper does not (Lessig, 2001, p. 122). There are a number of basic differences between information on the Internet and information preserved in hard copy. On the Internet, documents can be constantly updated, linked to other documents or web pages, and saved electronically for future reference and easy duplication. However, a printed book does not depend on an Internet connection, cannot be easily changed and therefore may be more reliable. The World Wide Web can be accessed from anywhere there is a connection to the Internet and a device capable of handling the exchange of information. A book, on the other hand, possesses an unquantifiable tactile appeal for those equipped to appreciate it. Much information on the Internet is free, though certainly not all, and sources must be evaluated for trustworthiness, as self-publishing is rampant. Yet printed material may be perceived as less expensive when compared with the cost of a subscription database or maintaining and making accessible vast amounts of electronic text. Some people may be attracted to one format or the other for some of these reasons or a variety of different ones.

\section{What happens when we read?}

Wolf (2007) writes that learning to read has helped to change the way we think as a species. She investigates "what our brain had to learn, one new process and insight at a time," moving through the development of writing systems (p. 25).The way textual information is presented 
today has changed dramatically from the ancient clay tablets where Wolf begins her research, but she examines major shifts in literacy and the tools which make it possible to disseminate information, including electronic formats. Today there is a clash between electronic and print formats. On both sides there are strong opinions and a variety of interpretations about what it means to be literate in today's digitally based information society.

As a starting point for her work, Wolf draws on the French novelist Marcel Proust's writing on the profound importance of time spent reading. In his 1905 article, "On Reading," published in Renaissance Latine, a French magazine, Proust ruminates about the impact of hours devoted to reading as a child, and the associations that come to exist between the stories that we read and the age at which we read them (Proust, 1905/1971). The place where reading occurs is also of crucial importance in the experience of reading that Proust describes; if reading takes place at the same computer terminal day after day, something is lost in the associative quality of that reading, as Proust understood it. The experience of reading varies dramatically between media. Is the way we process the information we read also changing, depending on the media in which we view text?

Naomi Baron (2008) emphasizes the importance of the content of reading as well as the context:

To read is not simply to happen upon information but to encounter ideas or turns of phrase that affect us intellectually or emotionally. Zipping through the pages of USA Today is a fundamentally different experience from grappling with James Joyce's Ulysses. (pp. 187-188)

Baron doesn't specify whether she is referring to print or electronic versions of these works, but acknowledges that the brain must function in different ways to process various types of text. Electronic text, laden with hyperlinks that compete for the reader's attention, take Baron's comparison of a newspaper to a work of modernist literature to another level. If quickly perusing the pages of a national daily newspaper is not conducive to deeper introspection, what of the way we read online? Some brains struggle to keep up with the constant influx of data.

Carr (2008b) writes, "Over the past few years l've had an uncomfortable sense that someone, or something, has been tinkering with my brain, remapping the neural circuitry, reprogramming the memory." The specific context to which Carr refers is that of reading. Spending hours reading a lengthy narrative or immersing oneself in an extended treatment of a specific topic is becoming increasingly difficult for some people, in an age of digital distraction. Carr continues describing his attempts to read for more than a few pages: "I feel as if I'm always dragging my wayward brain back to the text. The deep reading that used to come naturally has become a struggle" (2008b).

Carr is not alone in his experience. The subject of how exposure to electronic text is changing the experience of reading in general is explored in increasing depth in literacy discussions and considerations of how the digital world is changing our society. Some feel that reading online "is not necessarily any less intellectually challenging than reading a book. It's just different, and 
it requires different skills" (Tapscott, 2009, p. 112). There is no doubt that reading digital text is different, but the lasting effects of this activity on the brain are unknown. The discussion that follows examines various stances in the ongoing debate revolving around literacy in the digital world and the impact of reading online on the brain.

\section{The human brain is plastic - and reading online is rewiring it}

Reading is a learned skill, rather than a genetically inherited one; the human brain has evolved over millennia to interpret symbols or pictures as representative of language (Wolf, 2007). As you read a printed page, "your eyes and brain are converting the print medium into signals you can process and recognize as letters and words with meaning" (Negroponte, 1995, p. 184).' Vision and speech are genetically preprogrammed into human brains, while "reading has no direct genetic program passing it on to future generations" (Wolf, 2007, p. 11). Though reading is not a genetically inherited trait, over time human society began to place value on literacy, and today it is nearly impossible to participate as a fully functioning member of society without reading and writing skills, at least at some basic level.

Unlike sharpening our vision in order to distinguish between friend or foe, prey or threat, reading is not a life-saving skill, in the hunter-gatherer era sense. However, as oral knowledge began to be recorded and human memory preserved beyond the lifespan of the existing generation, benefits emerged, largely in the form of knowledge that could then be conveyed more easily and to a wider audience. Wolf writes of early record-keeping efforts: "With each of the new writing systems, with their different and increasingly sophisticated demands, the brain's circuitry rearranged itself, causing our repertoire of intellectual capacities to grow and change in great, wonderful leaps of thought" (Wolf, 2007, p. 27).

The medical community continues to examine the plastic properties of the human brain in various contexts (Thomas, 2003), but it will take time to understand the true physical effects of reading online, as well as to understand the repercussions. Wolf writes that it is due to the human brain's "plastic design" that we can read at all, and "when reading takes place, that individual brain is forever changed, both physiologically and intellectually" (Wolf, 2007, p. 5). Wolf describes the evolution of the brain, and the relationship between some of the earliest examples of writing: ancient Sumerian and modern-day Chinese, which bear striking similarities. Once trained to read Chinese characters, even when presented with a completely different alphabet, for example, the Roman one used in the English language, the Chinese brain will use the same neuronal pathways that it associates with the act of reading, even when a native English speaker's brain uses very different pathways. Wolf writes, "The act of learning to read Chinese characters has literally shaped the Chinese reading brain. Similarly, much of how we think and what we think about is based on insights and associations generated from what we read" (2007, p. 5).

Beyond the physical evolution of our brains, the content that we choose to read shapes our minds in terms of the insights and connections that we make when we interpret what we read. The format in which we choose to view information influences what we remember and what connections are formed within the brain between the current text under scrutiny, and any related reading done in the past. The mind does a great deal of interpreting while reading 
takes place, as well as afterwards, when contemplation (conscious or subconscious) occurs. Carr writes, "The medium is not only the message. The medium is the mind. It shapes what we see and how we see it. The printed page, the dominant information medium of the past 500 years, molded our thinking" (Carr, 2008a, p. 228). Now that more reading is conducted online, it follows that this newer information medium is again shaping our interpretation of the information we're presented with.

\section{Processing power: Is reading online changing the way we handle information?}

Because they have the tools to question, challenge, and disagree, these kids are becoming a generation of critical thinkers. I can think of nothing more singularly important to the future of humanity. (Tapscott, 1998, p. 88)

There is a lively discussion, both in popular culture monographs and online sources ranging from established journalistic websites to personal blogs, regarding whether interacting with digital data and electronic text is changing the way we read, think, and process information. Wolf (2007) remarks that researchers are only just starting to consider, for example, what the effects of Internet browsing habits such as using the "back" button on the browser might be on the brain.

Wolf compares the plasticity of the human brain to a computer's hard disk, writing that when learning to process visual symbols as representative of language, the brain forms new connections, and this is "basically the equivalent of adding memory to our hard drive" (2007, p. 34). Johnson (2005) likens reading to exercising one's mental muscles; there is work to be done in not simply reading text but in processing and analyzing the presented information. James Paul Gee also points out how we speak of the brain as a "container" that we can put things into and remove things from (2004, p. 76). Over time, are our brains becoming more like computers?

Children are learning to use computers at younger and younger ages, as electronic devices capable of connecting to the Internet drop in price and become more central to everyday participation in society. The current Net Generation is considered to be those young people born roughly between 1977 and 1997, who have grown up surrounded by digital devices (Geraci \& Chen, 2007). Don Tapscott remarks that "The brain is particularly adaptable to outside influences in the first three years of life and then during teenage and early adult years, which is just when most Net Geners are immersing themselves in interactive technology 20 to 30 hours per week" (2009, p. 98). Tapscott's latest book, Grown Up Digital, introduces this generation of youth and discusses their impact on institutions and society as they flood educational systems and enter the workforce (2009).

Tapscott acknowledges research showing that the brain constantly evolves over an individual's lifespan, and focuses specifically on a study by neuroscientists Stanley and Matthew Kutcher, which describes the possibility that time "spent with digital technologies" by young people "may be changing the physical structure and functioning of their developing brains" (2009, pp. 2930 ). Available research which looks at the impact of digital submersion on young minds is 
minimal so far, but the field appears to be growing. Tapscott offers his personal view, which is supported by the Kutcher study, but based largely on observing young people at work and play, multitasking all day long: "Far from anesthetizing young brains, digital immersion can, in my opinion, help them to develop critical thinking skills, the ones you need to navigate in today's fast-paced information-saturated world" (2009, p. 111).

Tapscott maintains a positive outlook, but as Wolf points out, we don't yet know if "the splitsecond immediacy of information gained from a search engine and the sheer volume of what is available [will] derail the slower, more deliberative processes that deepen our understanding of complex concepts" (2007, p. 221). When so much information is now available instantaneously, and it is a simple matter to click on one search result only to be distracted by something unrelated on the screen, researchers simply do not yet know what the full effect will be on the human brain. For champions of literacy, the move away from traditional reading is unnerving, while for fans of the electronic format, the promise of an interactive digital society is exciting.

\section{Adaptability of next generation brains}

Those following the Net Generation will grow up with the next mutation of the Internet itself, characterized by the social networking sites which are so popular these days. Will they completely miss the opportunity to read printed materials, if they grow up in a home that does not prioritize reading, and go straight into a fully networked school system? Wolf writes "We must teach our children to be 'bitextual,' or 'multitextual,' able to read and analyze texts flexibly in different ways," and adds that instructing "children to uncover the invisible world that resides in written words needs to be both explicit and part of a dialogue between learner and teacher, if we are to promote the processes that lead to fully formed expert reading" in our society (2007, p. 226). Wolf does not consider the possibility that as the Net Generation enters adulthood and the workforce, society's idea of a fully literate member may be forced to change, as these new workers stretch the concept of literacy and do not conform to the old understanding.

Learning to deal with digital text as well as traditional text is critical, to Wolf's thinking. Of this "multitextual" framework that children need to learn, Gee writes, "Once we see this multiplicity of literacy (literacies), we realize that when we think about reading and writing, we have to think beyond print" $(2004$, p. 14). Context is key when attempting to bring ideas from various types of text together. An ability to multitask and switch between stimuli is also crucial for anyone dealing with electronic text (Tapscott, 2009). As distractions online proliferate, and Internet users become more accustomed to following links as they appear, they forfeit some of the critical thinking skills honed through traditional reading in depth, assuming these skills were learned to begin with (Wolf, 2007).

\section{Does exposure to more information make the brain smarter?}

In The Big Switch, Carr (2008) predicts that in the future, data storage and computational power will flow in and out of homes and businesses like electricity. Rather than store our data on individual hard drives, it will be more cost-effective and convenient to store information 
offsite with private companies who will provide access for a fee, allowing the user to interact with that data from anywhere with an Internet connection and the necessary hardware. With access to a lifetime's worth of collected data -- images, text, video -- both self-produced and collected from myriad other sources, will the resulting wealth of information be of any use? And will our brains be equipped to organize it practically or will we be snowed under by the sheer volume of data one person can amass?

Wolf (2007) writes that reading is one of the most "powerful mirrors of the human brain's astonishing ability to rearrange itself to learn a new intellectual function" (pp. 4-5). She discusses both the enormous physiological changes that occurred in the human brain as it evolved its language centers before reading became a common skill, and the continuing alteration of the physical makeup of the brain as interaction with electronic media becomes more common. Wolf argues, "Knowing what reading demands of our brain and knowing how it contributes to our capacity to think, to feel, to infer, and to understand other human beings is especially important today as we make the transition from a reading brain to an increasingly digital one" (2007, p. 4). Those who are researching may well recognize the importance of reading, but do those who are simply soaking up available data realize how they are affected by the structure of their reading material and the format of the information they're exposed to?

A study carried out by University College London (UCL) researchers measured the extent that London cab drivers' brains develop in the areas associated with spatial reasoning skills and memory, so critical to their employment responsibilities (BBC, 2000). The researchers concluded that the extra pathways formed in pertinent areas of the brain were significant, and a direct result of on-the-job activities. Gee notes that "human beings think and reason in terms of patterns they have picked up from their experiences in the world" (2004, p. 177). Thus, the more a particular type of mental process is activated, whether it be spatial, verbal, reactive, or switching between multiple tasks, when one area of the brain is used to a greater extent that other parts, that area becomes more developed. Writing of the UCL cab driver study, Baron remarks, "By analogy, perhaps if we practice multitasking with language technologies, our brains will adapt, and performance on all the cognitive tasks will be laudatory" (2008, p. 40). Scientific efforts are now attempting to measure the magnitude of these neurological changes, comparing Net Generation brains to those less saturated in digital information.

A more recent study also undertaken by UCL researchers looks at the "Google Generation" (which the study defines as those born after 1993) and the ability of these young people to effectively use electronic resources in their studies and social interactions (Rowlands, et al., 2008). In a section on multitasking, the report writers note: "it is likely that being exposed to online media early in life may help to develop good parallel processing skills. The wider question is whether sequential processing abilities, necessary for ordinary reading, are being similarly developed" (Rowlands et al., 2008, p. 18). The researchers were not able to determine whether faster processing skills coincided with the development of the ability to follow a logical flow, for example of an extended narrative.

Tapscott acknowledges this inconclusive result, though he emphasizes that exposure to more information and the necessity of selectivity in processing has contributed to increased IQ scores in comparison to past generations: "This generation has been flooded with information, 
and learning to access, sort, categorize, and remember it all has enhanced their intelligence" (2009, p. 30). As Tapscott is not a scientist, his opinions should be considered in the light of social commentary rather than medical fact. Committed as he may be to the belief that "Net Geners," as he refers to them throughout Grown Up Digital, are more intelligent, Tapscott cannot affirm that the new generation of digitally-literate young people are capable of turning the data they're constantly exposed to into knowledge. Tapscott is correct, however, in stating that studies such as these "support the idea that continual and intense use of a particular brain region can lead it to respond like a muscle, increasing its size and presumably its efficiency" (2009, p. 99).

Information gathering and exposure to fast-moving data are not the only aspects of a digital society that is impacting young brains. Johnson has written at length about the role of video games in developing problem solving skills, especially in children and teenagers (2004). Johnson also credits video and computer games with helping to focus the attention of young people, engaging users in problem-solving tasks that have a clear goal, and participating in strategy that involves fast and flexible decision making. To his mind, these skills are critical for the future workforce, along with elements of team-building and teamwork as well. For Johnson, these skills indicate that exposure to digital complexity is an advantage.

\section{Does reading online slow the brain down?}

Michael Gorman $(2000,2003)$, an experienced educator in the library services field and American Library Association president from 2005-2006, despairs that with rising levels of exposure to digital media, children today are not fully literate in traditional media. He celebrates the value of book reading for the effect it has on improving the mind, declaring that "the sustained reading of complex texts [is] as necessary to the developed mind as are air, water and food to the healthy body" and that to devote time to reading "is a way of developing the mind, and the interpretation of texts is a rewarding intellectual activity in itself" (2000, p. 120). Gorman considers it crucial to understand the concept of literacy as more than merely the capability to read, write, and explore the Internet. He continues, "However much the latter may matter to living in 'an information society,' it cannot reasonably be assigned the importance of the sustained reading or writing of complex texts" (2003, p. 45). Without welldeveloped reading and writing skills, an Internet user will not be able to fully contribute to an information-based society. As Lee Siegel observes, "you can possess a lot of information about something without understanding it. An excess of information can even disable knowledge" because the mind is too distracted to make the data useful (2008, p. 150).

One of Gorman's biggest frustrations is the willingness of the masses to allow themselves to be "sedated by electronic diversions" (2003, p. 117). He cannot equate the reading of traditional literature with text available electronically, though Gorman does not go into specific details about how such evaluation might be undertaken, simply commenting that "The idea that something read and absorbed over time is inferior to something that is perused, and probably forgotten, in an instant is deeply flawed and deeply injurious" (Gorman, 2003, p. 125). Gorman believes that time is needed to consider the ideas that reading presents to the reader, in order for the mind to accommodate the new information and incorporate it into an individual's frame of reference. Reading electronically may discourage the reader from taking appropriate time to 
reflect, when there are so many demands on one's attention.

These comments of Gorman's are now several years old, and the debate about the importance of reading, both online and off, is ongoing. Gorman is not alone in declaring reading online to be deficient when compared to the act of reading a physical book or other materials where there tends to be time for reflection. Carr writes, "The Net provides no incentive to stop and think deeply about anything, to construct in our memory that 'dense repository' of knowledge" that is valued for learning (2008a, p. 228). There is no doubt that the Internet relies heavily on text, and so of course users need to be functionally literate, but there is also the fact that the level of necessary reading ability varies widely according to the audience the website is intended for (Mossberger, Tolbert, \&amp; McNeal, 2008). Lack of well-developed reading skills can prevent the user from fully participating in the electronic medium: "Limited literacy may pose a substantial barrier" to "the effectiveness of some who do go online" (Mossberger et al., 2008 , p. 15). The Internet these days is based to a great extent on images and therefore if a user chooses not to follow the text of a site, there is often still plenty to look at. The proliferation of heavily image-based websites makes it even easier for users to eschew reading and assimilating data, which detracts from the overall value of the information and poses less of a challenge to those who have trouble reading.

\section{Conclusions: Can we balance online and offline reading?}

Reading, an activity that is routine to most of us, is in truth miraculous and should be cherished and encouraged. (Gorman, 2000, p. 120)

Is this a choice that those who would read in the digital age must make, between reading in hard copy and reading online in the evolving electronic formats? Douglas Rushkoff writes of our intellectual interactions with the digital era, "if we can come to understand this tumultuous period of change as a natural phase in the development of new kinds of intelligence and crosscultural intimacy, then our imaginative and creative abilities are the only limits on our capacity for adaptation" (2006, p. 13). We need to find a balance between reading online and offline, a way to combine information assembled from both types of media, and to bring it together to inform our personal knowledge base. Constant exposure to digital data is not conducive to assimilation of information, so perhaps a sense of respect for taking the time to comprehend and consider data needs to be encouraged.

After examining the current popular culture discussion regarding the Net Generation's interaction with digital culture, some conclusions can be drawn regarding this issue. The good news about reading online is that it challenges our brains, forcing our minds to stretch their capacity for forming mental connections between pieces of information, and finding new methods of problem-solving in a collaborative setting. Also, as Carr notes, access to resources online is a boon for researchers, making searches fast and relatively painless (2008b). When used responsibly and thoughtfully, the proliferation of available information is incredibly helpful.

The not-so-good news is that with the dominance of digital media, our mental muscles are struggling to keep up with the fast pace of the introduction of new information, and our longterm memory may not be storing all that data as well as it would if we took longer assimilating 
the information. Young people who have not had the opportunity of growing up with exposure to longer narrative works and the logical progression they tend to build upon have a different way of processing information than previous literate generations, according to new neurological studies (Rowlands et al., 2008).

The slightly disturbing news is that if we don't attempt to maintain both kinds of literacy, Internet users' brains will likely shift away from in-depth reading and lose a whole level of comprehension (Carr, 2008; Wolf, 2007). Teachers, literacy workers, and librarians must be aware that there are unique challenges looming with regard to new formats of reading. The Net Generation, now growing up with less exposure to the traditional understanding of immersion in reading and literature, may discover narrative formats later in life, and find challenges in adapting to the traditional formats just as the generations of adults who have not grown up surrounded by digital media may not find it intuitive to participate in the interactive Internet. 


\section{References}

Baron, N. S. (2008). Always on: Language in an online and mobile world. Oxford, England: Oxford University Press.

BBC News World Edition. (2000, March 14). Taxi drivers' brains 'grow' on the job. Retrieved from http://news.bbc.co.uk/2/hi/science/nature/677048.stm

Carr, N. (2008a). The big switch: Rewiring the world, from Edison to Google. New York: W. W. Norton.

Carr, N. (2008b, July/August). Is Google making us stupid? What the Internet is doing to our brains. The Atlantic. Retrieved from http://www.theatlantic.com/doc/200807/google

Gee, J. P. (2004). What video games have to teach us about learning and literacy. New York: Palgrave Macmillan.

Geraci, J., \& Chen, L. (2007, July). Meet the global net generation. New Paradigm Learning Corporation. Retrieved from http://www.newtmn.com/sitebuildercontent/ sitebuilderfiles/meet_the_global_net_generation.pdf

Gorman, M. (2000). Our enduring values: Librarianship in the 21st century. Chicago: American Library Association.

Gorman, M. (2003). The enduring library: Technology, tradition, and the quest for balance. Chicago: American Library Association.

Johnson, S. (1997). Interface culture: How new technology transforms the way we create and communicate. New York: Basic Books.

Johnson, S. (2004). Mind wide open: Your brain and the neuroscience of everyday life. New York: Scribner.

Johnson, S. (2005). Everything bad is good for you: How's today's popular culture is actually making us smarter. New York: Riverhead Books.

Lessig, L. (2001). The future of ideas: The fate of the commons in a connected world. New York: Random House.

Mossberger, K., Tolbert, C. J., \& McNeal, R. S. (2008). Defining digital citizenship. Digital citizenship: The Internet, society, and participation (pp. 1-19). Cambridge, MA: MIT Press.

Negroponte, N. (1995). Being digital. New York: Knopf.

Proust, M. (1971). On reading (J. Austret, \& W. Burford, Trans., Eds.). New York, 
Macmillan. (Original work published 1905).

Rowlands, I., Nicholas, D., Williams, P., Huntington, P., Fieldhouse, M., Gunter, B., et al. (2008). The Google generation: The information behaviour of the researcher of the future. Aslib Proceedings, 60(4) Retrieved from http://www.emeraldinsight.com/10.1108/ 00012530810887953

Rushkoff, D. (2006). ScreenAgers: Lessons in chaos from digital kids. Cresskill, NJ: Hampton Press.

Siegel, L. (2008). Against the machine: Being human in the age of the electronic mob. New York: Spiegel \& Grau.

Tapscott, D. (1998). Growing up digital: The rise of the net generation. New York: McGraw-Hill.

Tapscott, D. (2009). Grown up digital: How the net generation is changing the world. New York: McGraw-Hill.

Thomas, M. S. C. (2003). Limits on plasticity. Journal of Cognition and Development. 4, (1), 99 125. Retrieved February 26, 2009, from Academic Search Premier database. Warlick, D. (2004). Redefining literacy for the 21st century. Worthington, OH: Linworth Pub.

Wolf, M. (2007). Proust and the squid: The story and science of the reading brain. New York: HarperCollins.

' Over a decade ago, Negroponte actually did compare proficiency in the digital age with genetically transferred abilities, writing that being digital "is almost genetic in its nature, in that each generation will become more digital than the preceding one" (1995, p. 231). Provocative though this statement may be, more recent research simply reinforces a general understanding that children are very receptive to learning new skills at young ages (Warlick, 2004), and early exposure to information technology results in corresponding strengths in digital platforms (Johnson, 2005). 